\title{
Retraction Note to: Fractional order Lengyel-Epstein chemical reaction model
}

\section{Zain UI Abadin Zafar ${ }^{1}$}

Published online: 16 April 2020

(c) SBMAC - Sociedade Brasileira de Matemática Aplicada e Computacional 2020

\section{Retraction Note to: \\ Computational and Applied Mathematics (2019) 38:131 https://doi.org/10.1007/s40314-019-0887-4}

The Editor-in-Chief has retracted this article Zafar (2019) because it shows significant overlap with a previously published article Daşbaşi and Daşbaşi (2017). The author, Zain Ul Abadin Zafar does not agree to this retraction.

\section{References}

Daşbaşi B, Daşbaşi T (2017) Mathematical analysis of Lengyel-Epstein chemical reaction model by fractionalorder differential equation's system with multi-orders. Int. J. Sci. Eng. Invest. 6:50

Zafar ZUA (2019) Fractional order Lengyel-Epstein chemical reaction model. Comp. Appl. Math. 38:131. https://doi.org/10.1007/s40314-019-0887-4

Publisher's Note Springer Nature remains neutral with regard to jurisdictional claims in published maps and institutional affiliations.

The original article can be found online at https://doi.org/10.1007/s40314-019-0887-4.

Z Zain Ul Abadin Zafar

zainzafar2016@hotmail.com

1 Faculty of Information Technology, University of Central Punjab, Lahore, Pakistan 